\title{
ARTIFICIAL NEURAL NETWORK (ANN) APPROACH TO PREDICTION OF DIFFUSION BONDING BEHAVIOR (SHEAR STRENGTH) OF NI-TI ALLOYS MANUFACTURED BY POWDER METALURGY METHOD
}

\author{
Mustafa Taskin, Halil Dikbas and Ugur Caligulu \\ Department of Metal, Faculty of Technical Education, University of Firat, 23119 \\ Elazığ, Turkey.mtaskin@firat.edu.tr
}

\begin{abstract}
In this study, Artificial Neural Network approach to prediction of diffusion bonding behavior of Ni-Ti alloys, manufactured by powder metallurgy process, were obtained using a back-propagation neural network that uses gradient descent learning algorithm. Ni-Ti composite manufactured with a chemical composition of $51 \% \mathrm{Ni}-49$ $\% \mathrm{Ti}$ in weight percent as mixture with a average dimension of $45 \mu \mathrm{m}$. Diffusion welding process have been made under argon atmosphere, with a constant load of 5 $\mathrm{MPa}$, under the temperature of $850,875,900$ and $925^{\circ} \mathrm{C}$ and, in 20,40 and 60 minutes experiment time. Microstructure examination at bond interface were investigated by optical microscopy, SEM and EDS analysis. Specimens were tested for shear strength and metallographic evaluations. After the completion of experimental process and relevant test, to prepare the training and test (checking) set of the network, results were recorded in a file on a computer. In neural networks training module, different temperatures and welding periods were used as input, shear strength of bonded specimens at interface were used as outputs. Then, the neural network was trained using the prepared training set (also known as learning set). At the end of the training process, the test data were used to check the system accuracy. As a result the neural network was found successful in the prediction of diffusion bonding shear strength and behavior.
\end{abstract}

Key Words- ANN, Ni-Ti, Diffusion Bonding, Shear Strength, Powder Metallurgy.

\section{INTRODUCTION}

Recently, with the developments in artificial intelligence; researchers have a great deal of attention to the solution of non-linear problems in physical and mechanical properties of metal alloys [1]. Researchers are putting much emphasis on the manufacturing, shaping, bonding problems to widespread the use of composites in common industry markets. The produce of composites, Ni-Ti alloys to have been used with powder metallurgy method and which produce of composites, determine of using field important to present [2]. Joining of the powder metallurgy products $(\mathrm{P} / \mathrm{M})$ by diffusion bonding process is important both to protect the microstructural properties of parent materials and bonding behavior of joining materials [3]. Diffusion bonding is a solid state coalescence of contacting surfaces occurs at a temperature below the melting point $\left(0,5-0,7 \mathrm{~T}_{\mathrm{m}}\right)$ of the materials to be joined with the loads and the period, below those that would cause macro deformation and a significant properties change at the parent materials. The process is depended on a number of parameters in particular, bonding temperature, atmosphere, time, pressure and surface roughness. Process pressure is selected high enough to dislocate the surface oxides. Bonding period should 
be selected long enough for the completion of the diffusion mechanism at the interface. Diffusion bonding is an advanced bonding process in which two materials, similar or dissimilar, can be bonded in solid state [4-5].

In recent years artificial neural networks (ANNs) have emerged as a new branch of computing, suitable for applications in a wide range of fields. Artificial neural networks have been recently introduced into tribology by Jones et al. [6-7]. In this study, experimental and ANNs results have been compared. A lot of studies have been published in which the prediction of various parameters on Ni-Ti alloys. Egercioglu et al. were investigated prediction of martensite and austenite start temperatures of the Febased shape memory alloys by artificial neural networks [8]. Zambaldi et al. were investigated modeling and experiments on the indentation deformation and recrystallization of a single-crystal nickel-base superalloy [9]. Karthikeyan et al. were investigated modeling microtwinning during creep in Ni-based superalloys [10].

In this study, features of multi layer perceptron architecture with backpropagation learning algorithm were employed to predict the shear strength of diffusion bonding behavior of Ni-Ti alloys manufactured by $\mathrm{P} / \mathrm{M}$ process.

\section{ARTIFICIAL NEURAL NETWORK}

Computers are an integral part of day to day activities in engineering design and engineers have utilized various applications to assist them improve their design [11-12]. ANN mimic some basic aspects of the brain functions. ANNs are based on the neural structure of the human brain, which processes information by means of interaction between many neurons and in the past few years there has been a constant increase in interest of neural network modeling in different fields of materials science. The basic unit in the ANNs is the neuron. The neurons are connected to each other with weight factor [13-14].

Artificial neural networks (ANNs) are networks of highly interconnected neural computing elements that have the ability to respond to input stimuli and to learn to adapt to the environment. ANN includes two working phases, the phase of learning and that of recall. During the learning phase, known data sets are commonly used as a training signal in input and output layers. The recall phase is performed by one pass using the weight obtained in the learning phase. ANN is now a well established tool and details about it can be found elsewhere. Various nomenclatures are used to describe neural network paradigms [15-16-17]. Whereas, a single-layer network has single input/output units, a multi-layer network has one or more hidden units between input and output layers (Figure 1).

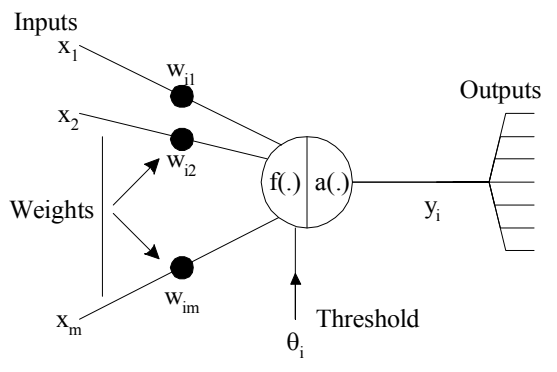

Figure 1. The mathematical model of neuron 
A Back Propagation (BP) Neural Network is a multi-layer neural network which uses gradient-descent technique analogous to error minimization. A neural network is characterized by the pattern of connections between the neurons; this is called the network architecture. Various network architectures are available. The information included in the illustration data was acquired via the improved back propagation (BP) learning algorithm. The parameters of the BP network were defined as follows:

The input vectors $[\mathrm{X}=\mathrm{x} 0, \mathrm{x} 1, \ldots, \mathrm{xn} 1]^{\mathrm{T}}$

The output vectors $[\mathrm{Y}=\mathrm{y} 0, \mathrm{y} 1, \ldots, \mathrm{ym} 1]^{\mathrm{T}}$

where the symbols $\mathrm{n}, \mathrm{h}$ and $\mathrm{m}$ represented the number of neurons in the input layer, the hidden layer and the output layer, sequentially [18-19-20].

\section{MATERIALS and EXPERIMENTAL PROCEDURE}

\subsection{Fabrication of Ni-Ti MMCs}

$\mathrm{Ni}$-Ti composite manufactured with a chemical composition of $51 \% \mathrm{Ni}-49 \%$ $\mathrm{Ti}$ in weight percent as mixture with a average dimension of $45 \mu \mathrm{m}$. Powders were properly mixed with mechanic mixers at $1000 \mathrm{rpm}$ for 30 minutes for homogeneity of the formation. The mixture was cold compacted at $619 \mathrm{MPa}$ in the $\phi 12 \times 10 \mathrm{~mm}$ steel dies. This is followed by sintering at $950^{\circ} \mathrm{C}$ in argon atmosphere for 30 minutes [2].

\subsection{Diffusion Bonding of Ni-Ti MMC Couples}

Work pieces were prepared for diffusion bonding and surfaces to be joined were protected against corrosion and oxidation. The manifactured samples were joined by use diffusion welding technique. The bonding of composite material parts were relaized under the constant pressure, at different temperatures and durations. Diffusion welding process have been made under argon atmosphere, with a constant load of $5 \mathrm{MPa}$, under the temperature of $850,875,900$ and $925^{\circ} \mathrm{C}$ and, in 20,40 and 60 minutes experiment time. Schematic illustration of diffusion bonding apparatus is given in Figure 2.

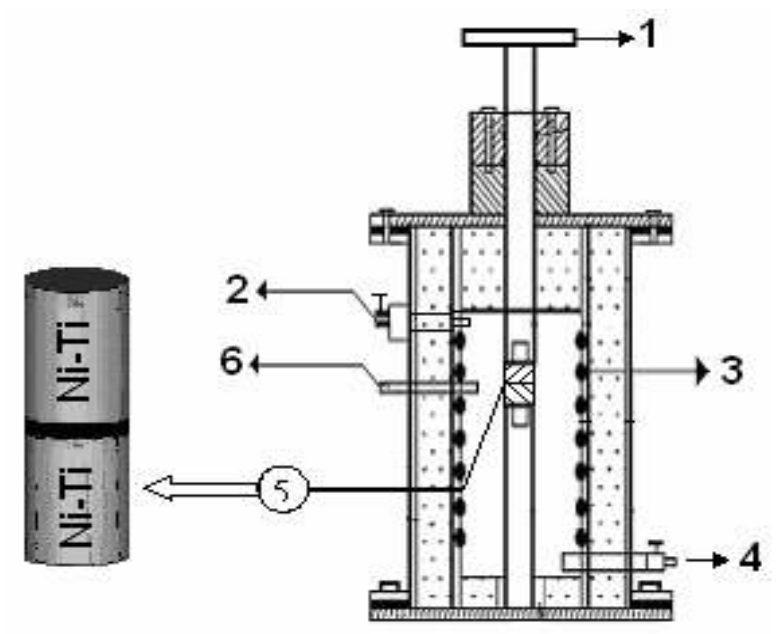

1-Load 2-Argon Outlet 3-Heat Coil 4-Argon Inlet 5-Specimens 6-Thermocouple

Figure 2. Schematic illustration of diffusion bonding apparatus [21]. 


\subsection{Microstructure Examinations and Shear Strength Tests}

After the bonding process, specimens were tested for shear strength. The schematic illustration of shear strength test apparatus is given in Figure 3. Specimens were cut perpendicular to the bonding interface to facilitate longitudinal microstructure cross section examinations. Grinding of the surface was followed by etching with 200 $\mathrm{ml}$ pure water, $10 \mathrm{gr}$ Amonyum Persülfat, $10 \mathrm{gr} \mathrm{KCN}$ etchant. Metallographic evaluations and investigations were made by the aid of optical microscopy and SEM.

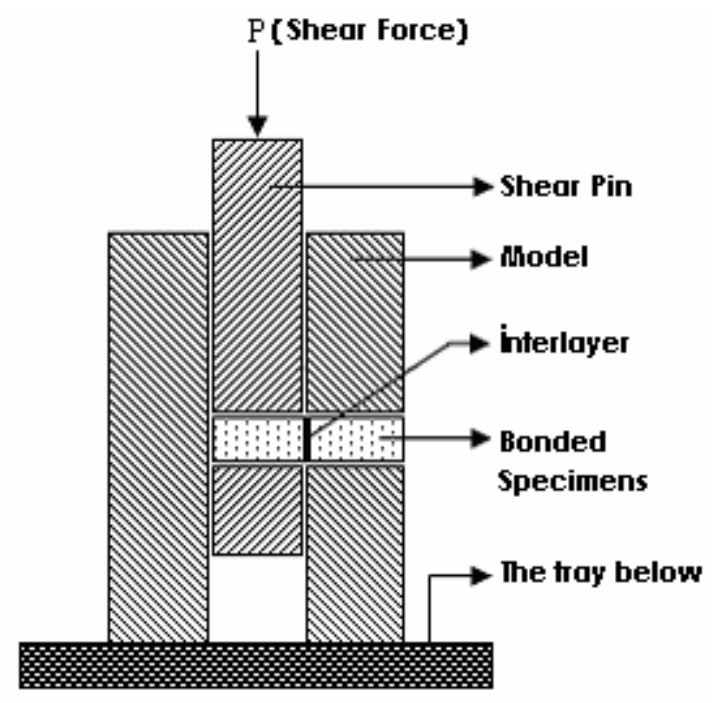

Figure 3. Schematic illustration of shear strength testing apparatus [22].

\subsection{Modelling with neural networks}

Modeling of shear strength of diffusion bonding behavior at MATLAB program diffusion bonding period and process temperature were employed as input and shear strength of the bonded interfaces were recorded as output parameters. Back propagation Multilayer Perceptron (MLP) ANN was used for training of experimental results. ANN modeling the shear strength of the interface of diffusion bonded composite was carried out with the aid of ANN block diagram given at Figure 4. MLP architecture and training parameters were presented in Table 1.

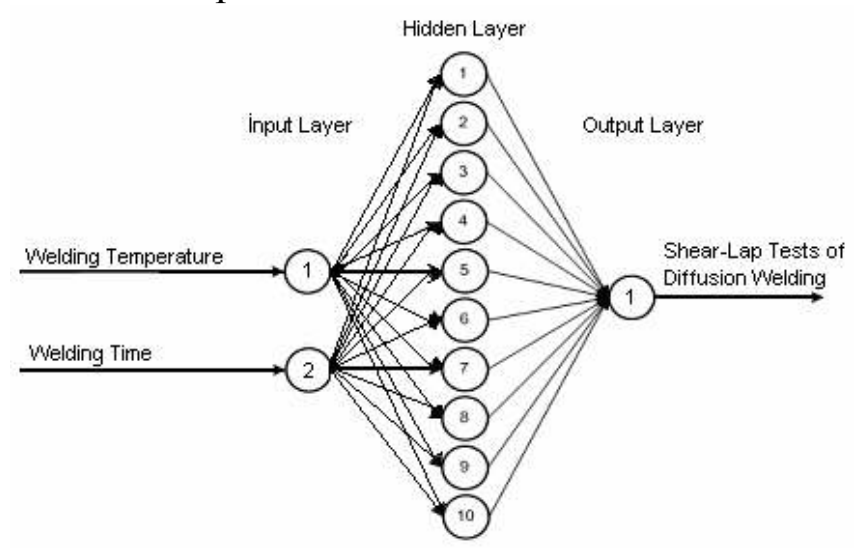

Figure 4. Block diagram of the ANN. 
Table 1. MLP architecture and training parameters

\begin{tabular}{|ll|}
\hline The number of layers & 2 \\
The number of neuron on the layers & Input: 2, Hidden: 10, Output: 1 \\
The initial weights and biases & Randomly between -1 and +1 \\
Activation functions for hidden and output layers & Log-sigmoid \\
Training parameters Learning rule & Back-propagation \\
Adaptive learning rate for hidden layer & 0.9 \\
Adaptive learning rate for output layer & 0.7 \\
Number of iteration & 6780 \\
Momentum constant & 0.95 \\
Duration of learning time & 2 minutes 8 seconds \\
Acceptable mean-squared error & 0.001 \\
\hline
\end{tabular}

\section{RESULTS and DISCUSSION}

In thus study, the effect of the joining on the diffusion bonding behavior of Ni-Ti alloys manufactured by powder metalurgy method were investigated. The strength of the joints tested by shear-lap tests. The following results were obtained.

\subsection{Evaluation of Bond Integrity and Parameters}

Deformation of surface asperities by plastic flow and creep, grain boundary diffusion of atoms to the voids and grain boundary migration, volume diffusion of atoms to voids can be listed as a sequence of metallurgical stages of the diffusion bonding. Especially with Ni-Ti alloys diffusion bonding can be achieved with adherent surface oxides. In general, the oxide is not removed, but is simply dispersed over a greater surface area in an enclosed environment, in which oxidation cannot recur.

At elevated temperatures diffusion mechanism were accelerated and diffusion period were decreased to achieve the same coalescence. at Figure 5.

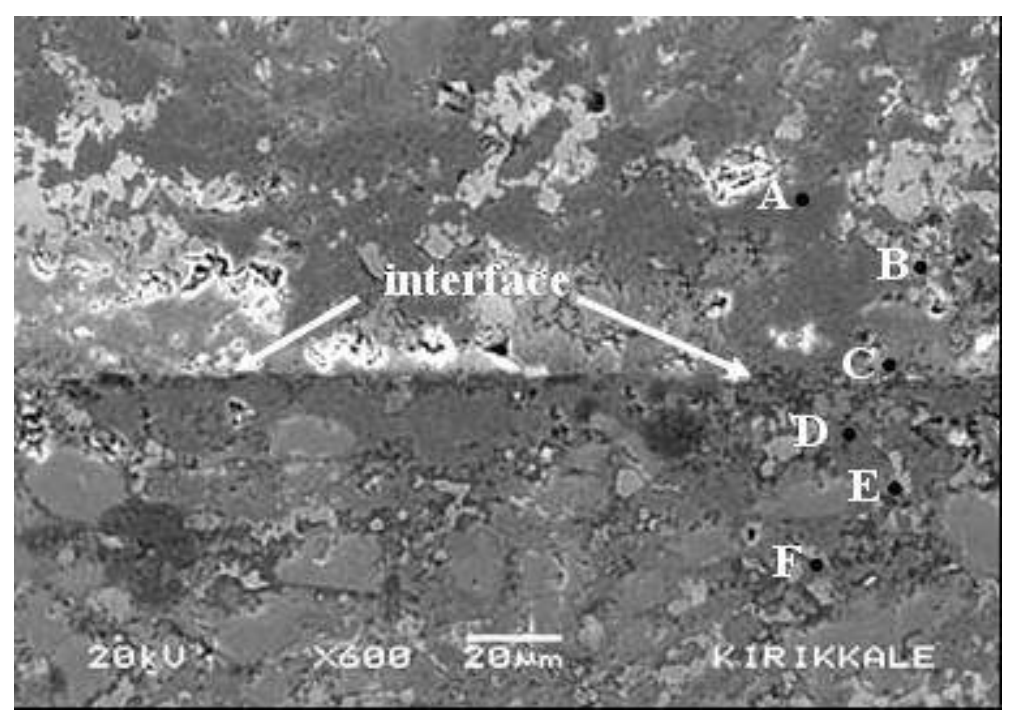

Figure 5. One of the SEM micrography specimen bonded 


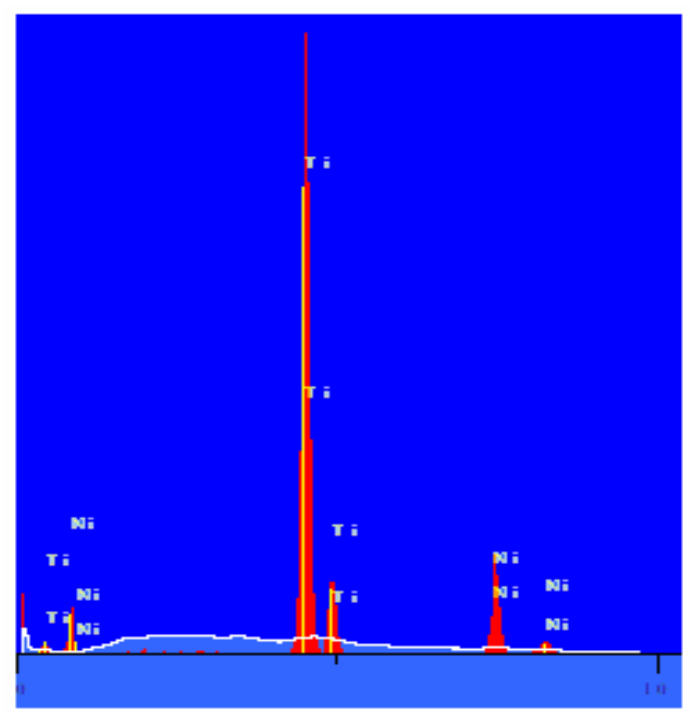

\begin{tabular}{|c|c|c|c|c|c|}
\hline $\begin{array}{c}\text { Point of } \\
\text { analysis }\end{array}$ & Elt & Line & $\begin{array}{c}\text { Intensity } \\
(\mathbf{c} / \mathbf{s})\end{array}$ & $\begin{array}{c}\text { Conc } \\
(\mathbf{w t})\end{array}$ & $\begin{array}{c}\text { Atomic } \\
(\mathbf{\%})\end{array}$ \\
\hline \multirow{2}{*}{$\mathbf{A}$} & $\mathrm{Ti}$ & $\mathrm{Ka}$ & 732.29 & 46.038 & 51.127 \\
\cline { 2 - 6 } & $\mathrm{Ni}$ & $\mathrm{Ka}$ & 270.41 & 53.962 & 48.873 \\
\hline \multirow{2}{*}{$\mathbf{B}$} & $\mathrm{Ti}$ & $\mathrm{Ka}$ & 697.48 & 41.252 & 46.224 \\
\cline { 2 - 6 } & $\mathrm{Ni}$ & $\mathrm{Ka}$ & 308.67 & 58.848 & 53.776 \\
\hline \multirow{2}{*}{$\mathbf{C}$} & $\mathrm{Ti}$ & $\mathrm{Ka}$ & 697.48 & 41.252 & 46.224 \\
\cline { 2 - 6 } & $\mathrm{Ni}$ & $\mathrm{Ka}$ & 308.67 & 58.848 & 53.776 \\
\hline \multirow{2}{*}{$\mathbf{D}$} & $\mathrm{Ti}$ & $\mathrm{Ka}$ & 752.24 & 44.726 & 49.804 \\
\cline { 2 - 6 } & $\mathrm{Ni}$ & $\mathrm{Ka}$ & 291.60 & 55.274 & 50.196 \\
\hline \multirow{2}{*}{$\mathbf{E}$} & $\mathrm{Ti}$ & $\mathrm{Ka}$ & 542.03 & 46.089 & 51.179 \\
\cline { 2 - 6 } & $\mathrm{Ni}$ & $\mathrm{Ka}$ & 229.55 & 53.911 & 48.821 \\
\hline \multirow{2}{*}{$\mathbf{F}$} & $\mathrm{Ti}$ & $\mathrm{Ka}$ & 776.75 & 43.448 & 48.508 \\
\cline { 2 - 6 } & $\mathrm{Ni}$ & $\mathrm{Ka}$ & 315.14 & 56.552 & 51.492 \\
\hline
\end{tabular}

Figure 6. One of the EDS analysis of specimens bonded

\subsection{ANN Approach to Shear Strength Prediction}

In this study, predictions of shear strength of diffusion bonded MMC couples were performed by using a back-propagation neural network that uses gradient descent learning algorithm. This experimental results have been compared with ANNs results. Iteration number has been selected 6780. Two input neurons, 10 neurons in the intermediate layers and 1 output neurons [2:10:1] have been selected for this study. The learning rate and momentum values have been selected as $0.5,1$, respectively.

a) Bonding process temperature and bonding period were used as the model inputs while the shear strength was the output of the model. These datas were obtained from experimental works.

b) Comparison of experimental shear strength test results with predicted values inline with bonding parameters were presented in Table 2. Experimental shear strength of specimen has shown a consistency with predicted results differing $0.5-1$. These trained values can lead maximum 6,653132\% error in shear strength calculations. 
ANN Approach to Prediction of Diffusion Bonding Behavior

Table 2. Shear strength of predicted values with actual values

\begin{tabular}{|c|c|c|c|c|l|l|}
\hline $\begin{array}{c}\text { Sample } \\
\text { No }\end{array}$ & $\begin{array}{c}\text { Couples } \\
\text { of } \\
\text { samples }\end{array}$ & $\begin{array}{c}\text { Temp. } \\
\left.\mathbf{(}^{\mathbf{O}} \mathbf{C}\right)\end{array}$ & $\begin{array}{c}\text { Durations } \\
\text { (min.) }\end{array}$ & $\begin{array}{c}\text { Actual } \\
\text { values of } \\
\text { shear } \\
\text { strength } \\
\left(\mathbf{K g} / \mathbf{m m}^{2}\right)\end{array}$ & $\begin{array}{c}\text { Predicted } \\
\text { values of } \\
\text { shear } \\
\text { strength } \\
\left(\mathbf{K g} / \mathbf{m m}^{2}\right)\end{array}$ & \% Error \\
\hline $\mathbf{1}$ & $\mathrm{Ni}-\mathrm{Ti}$ & 850 & 20 & 23 & 20,10075 & $+12,60543$ \\
\hline $\mathbf{2}$ & $\mathrm{Ni}-\mathrm{Ti}$ & 850 & 40 & 25 & 22,67325 & $+9,307$ \\
\hline $\mathbf{3}$ & $\mathrm{Ni}-\mathrm{Ti}$ & 850 & 60 & 27 & 23,02585 & $+14,71907$ \\
\hline $\mathbf{4}$ & $\mathrm{Ni}-\mathrm{Ti}$ & 875 & 20 & 29 & 27,356 & $+5,668966$ \\
\hline $\mathbf{5}$ & $\mathrm{Ni}-\mathrm{Ti}$ & 875 & 40 & 30 & 30,2974 & $-0,991333$ \\
\hline $\mathbf{6}$ & $\mathrm{Ni}-\mathrm{Ti}$ & 875 & 60 & 31 & 31,25805 & $-0,832419$ \\
\hline $\mathbf{7}$ & $\mathrm{Ni}-\mathrm{Ti}$ & 900 & 20 & 32 & 33,3393 & $-4,185313$ \\
\hline $\mathbf{8}$ & $\mathrm{Ni}-\mathrm{Ti}$ & 900 & 40 & 34 & 36,09215 & $-6,153382$ \\
\hline $\mathbf{9}$ & $\mathrm{Ni}-\mathrm{Ti}$ & 900 & 60 & 37 & 37,2846 & $-0,769189$ \\
\hline $\mathbf{1 0}$ & $\mathrm{Ni}-\mathrm{Ti}$ & 925 & 20 & 40 & 37,7805 & $+5,54875$ \\
\hline $\mathbf{1 1}$ & $\mathrm{Ni}-\mathrm{Ti}$ & 925 & 40 & 43 & 40,08505 & $+6,778953$ \\
\hline $\mathbf{1 2}$ & $\mathrm{Ni}-\mathrm{Ti}$ & 925 & 60 & 47 & 41,22945 & $+12,27777$ \\
\hline
\end{tabular}

c) The Sum-squared error (SSE) graphic trained for 6780 Epochs was presented in Figure 7. (a-b)

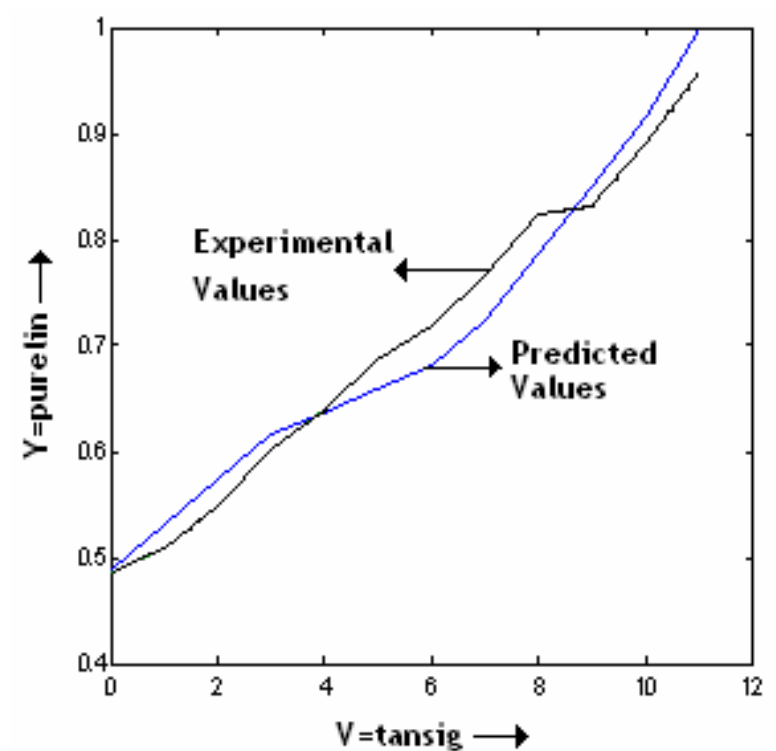

(a)

Figure 7. a- Comparison between the experimental and predicted values 


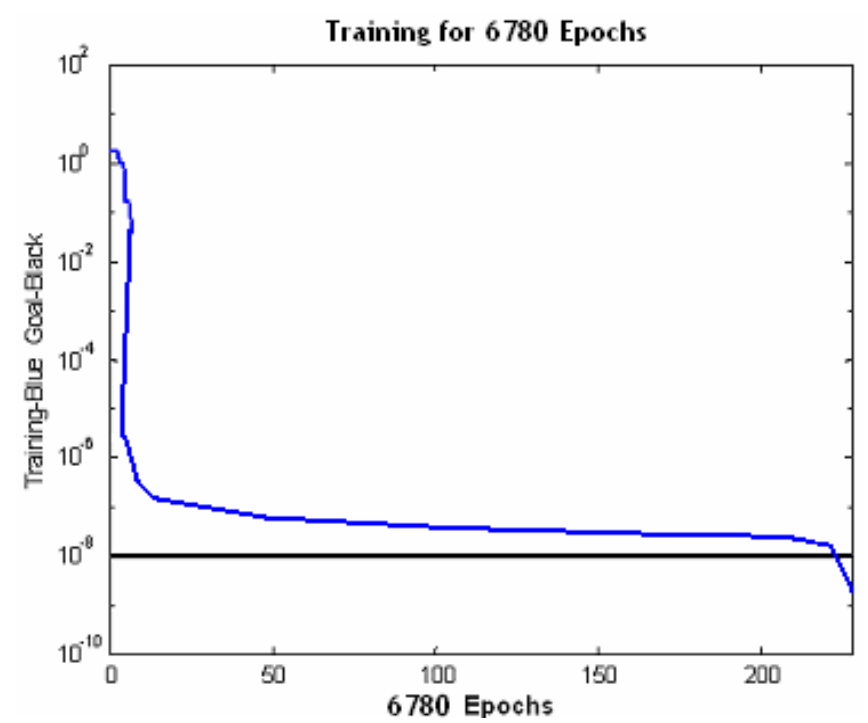

(b)

Figure 7. b- Sum-Squared error curve versus iteration number

\section{CONCLUSION}

The overall performance of the model was quite satisfactory. The low error fractions indicate that ANNs could be a useful tool for modeling and predicting shear strength of bonded interfaces of Ni-Ti alloy MMCs. Under given conditions, and with prescribed materials predicted shear strength can be utilized by designers and process engineers as and where necessary. Given and predicted values of the ANN system can also be employed at feasibility programs at no cost. This can be handled as a cost saving item at advanced production planning.

\section{REFERENCES}

1. Agrawal, G., Frost, J.D., Chameau, C.L.A., Data analysis and modeling using arti.cial neural network. In: Gulhati, S.K. (Ed.), Proceedings of XIII International Conference of Soil Mechanics and Foundation Engineering 4, New Delhi, 14411444, 1994.

2. Dikbas, H., The Investigation of Bondability of Ni-Ti Alloys by Powder Metallurgy Method with The Diffusion Bonding, Firat Uni. Graduate School of Naturel and Applied Sciences Department of Metallurgy Education, Master Thesis, Elazig, 2005.

3. Koker, R., Altinkok, N., Modelling of the prediction of tensile and density properties in particle reinforced metal matrix composites by using neural networks, Materials and Design, 1-7, 2005.

4. Taskin, M., Diffusion bonding of fine grained high carbon steels in the superplasticity temperature range, Firat University Graduate School of Naturel and Applied Sciences Department of Metallurgy Education, PhD Thesis, Elazig, 2000. 
5. Taskin, M. and Caligulu, U., Modelling of microhardness values by means of artificial neural networks of $\mathrm{Al} / \mathrm{SiCp}$ metal matrix composite material couples processed with diffusion method, Mathematical and Computational Applications 11(3), 163-172, 2006.

6. S.P. Jones, R. Jansen and R.L. Fusaro, Preliminary investigation of neural network techniques to predict tribological properties, Tribol Trans, 40,1997, (2), p. 312.

7. Durmuş, H., Özkaya, E. And Meriç C., The use of neural networks for the prediction of wear loss and surface roughness of AA6351 aluminium alloy, Materials and Desing 27, 156-159, 2006.

8. Eyercioglu, O., Kanca, E., Pala, M. and Ozbay E., Prediction of martensite and austenite start temperatures of the Fe-based shape memory alloys by artificial neural networks, Journal of Materials Processing Technology, 2007, In Press.

9. Zambaldi, C. Roters, F., Raabe D and Glatzel, U., Modeling and experiments on the indentation deformation and recrystallization of a single-crystal nickel-base superalloy, Materials Science and Engineering A 454-455, 433-440, 2007.

10. Karthikeyan, S., Unocic, R.R., Sarosi, P.M., Viswanathan,G.B., Whitis, D.D. and Mills M.J., Modeling microtwinning during creep in Ni-based superalloys, Scripta Materialia 54, 1157-1162, 2006.

11. M. Perzyk and A.W. Kochanski, Prediction of ductile cast iron quality by artificial neural networks, J Mater Process Technol 109, 305-307, 2001.

12. M.Y. Rafiq, G. Bugmann and D.J. Easterbrook, Neural network design for engineering applications, Comput Struct 79, 1541-1552, 2001.

13. S. Kenig, A. Ben-David, M. Öemr and A. Sadeh, Control of properties in injection molding by neural networks, Eng Appl Artif Intel 4, 819-823, 2001.

14. S.P. Jones, R. Jansen and R.L. Fusaro, Preliminary investigation of neural network techniques to predict tribological properties, Tribol Trans 40(2), 312, 1997.

15. Limpon, R.P., An introduction to computing with neural nets, IEEE ASSP Magazine, 4-22, 1987.

16. Nielsen, R.H., Neurocomputing, picking the human brain, IEEE Spectrum 25(3), 36-41, 1998.

17. Fausett, F., Fundamentals of Neural Networks: Architectures, Algorithms and Applications, Prentice-Hall, Englewood Cli.s, NJ, USA., 155-178, 1994.

18. Haykin, S., Neural Networks, A comprehensive Foundation, McMillian College Publishing Company, New York, 198-203, 1994.

19. Avci, E., Turkoglu I., and Poyraz, M., Intelligent target recognition on based wavelet packet neural network, Elsevier Expert Systems with Applications 29, 175$182,2005$.

20. Avci, E., Turkoglu I., and Poyraz, M., Intelligent target recognition based on wavelet adaptive network based fuzzy inference system, Lecture Notes in Computer Science 3522, Springer-Verlag, pp. 594-601, 2005.

21. Aydin, M., TR2002 02710 U Patented Diffusion Bonding Machine, Department of Machine Engineering, Faculty of Engineering, University of Dumlipinar, Kütahya, Turkey.

22. Kejanli, H., Investigation of Ni-Ti-Cu alloys combinability that produced by dust metallurgy method with liquid phase diffusion welding, Firat University Graduate School of Naturel and Applied Sciences Department of Metallurgy Education, PhD Thesis, Elazig, 2007. 